Perceptual and Motor Skills, 1995, 81, 287-296. (C) Perceptual and Motor Skills 1995

\title{
EFFECTS OF INTERVENTION UPON PRECOMPETITION STATE ANXIETY IN ELITE JUNIOR TENNIS PLAYERS: THE RELEVANCE OF THE MATCHING HYPOTHESIS '
}

\author{
PETER TERRY, LISA COAKLEY, AND COSTAS KARAGEORGHIS \\ School of Physical Education and Sport \\ Brunel University College, UK
}

\begin{abstract}
Summary.-The matching hypothesis proposes that interventions for anxiety should be matched to the modality in which anxiety is experienced. This study investigated the relevance of the matching hypothesis for anxiety interventions in tennis. Elite junior tennis players ( $N=100$; Age: $M=13.9$ yr., $S D=1.8$ yr.) completed the Competitive State Anxiety Inventory- 2 before and after one of four randomly assigned intervention strategies approximately one hour prior to competition at a $\mathrm{Na}$ tional Junior Championship. A two-factor multivariate analysis of variance (group $x$ time) with repeated measures on the time factor gave no significant main effect by group but indicated significant reductions in somatic anxiety and cognitive anxiety and a significant increase in self-confidence following intervention. A significant group by time interaction emerged for self-confidence. The results question the need to match intervention strategy to the mode of anxiety experienced.
\end{abstract}

It is generally accepted that competition anxiety can have negative effects upon athletic performance, with current research conceptualizing anxiety as a multidimensional construct comprising cognitive and somatic components (Hardy \& Jones, 1994; Martens, Burton, Vealey, Bump, \& Smith, 1990). Davidson and Schwartz's (1976) "multiprocess" model proposed that some types of stress-management techniques are more effective than others in counteracting particular symptoms of anxiety. Modified for sport, the model suggests that an athlete experiencing somatic anxiety in the form of localized muscle tension should utilize a physical relaxation technique such as progressive muscular relaxation, whereas one experiencing somatic anxiety in the form of butterflies or clammy hands should use an autogenic or controlled breathing technique. Similarly, cognitive anxiety manifested as overanalysis might be reduced by self-instructional "cue words," whereas cognitive anxiety in the form of negative images might necessitate mental rehearsal of the perfect performance (Burton, 1990).

This proposed compatibility between anxiety modality and type of intervention has become known as the matching hypothesis. Proponents of this hypothesis have recommended that intervention strategies to reduce

'This research was supported by funding from the Lawn Tennis Association. Address correspondence to Dr. P. Terry, Brunel University College, Borough Road, Isleworth, Middlesex TW7 5DU, United Kingdom. 
state anxiety should be matched to the target modality of the anxiety (Gould, Petlichkoff, \& Weinberg, 1984; Jones, 1992). Among athleric populations, Maynard and Cotton (1993) have provided the only published test of the matching hypothesis to date. They compared the effectiveness of applied relaxation (Ost, Jerremalm, \& Johansson, 1988), a somatic intervention, and positive thought control (Suinn, 1987), a cognitive intervention, in reducing state anxiety prior to a series of collegiate field hockey games. Their results supported the matching hypothesis, in that applied relaxation training significantly reduced somatic anxiety, while positive thought control significantly reduced cognitive anxiety. The authors noted that, "anxiety-reduction techniques direcred at one system also facilitated relaxation through the other system to a lesser degree" (Maynard \& Cotton, 1993, p. 384), supporting the notion of some crossover effect in which an intervention may also reduce symptoms in the less "compatible" modality of anxiety.

Maynard and Cotton (1993) acknowledged that the limited size of their sample restricted the generalizability of their results and called for further testing. Also, the extent of any crossover effect is not well understood, particularly with respect to anxiery reduction. The proposal, that the activation of one modality of anxiety acts as a stimulus for the activation of other modalities, is long established (Borkovec, 1976). The converse argument, that reduced cognitive anxiety acts as a stimulus for reduced somatic anxiety (and vice versa), appears equally tenable.

If the matching hypothesis does hold, the intervention process remains complex. If, however, a demonstrable crossover effect between anxiety subcomponents exists, it sumplifies the nature of interventions. The purpose of the present study was to assess the effectiveness of four intervention strategies in reducing competitive state anxiety among elite junior tennis players to evaluate the proposed desirability of matching type of intervention to mode of anxiety.

\section{Method}

Subjects

Participants were 100 elite junior tennis players (boys $=42$; girls $=58$ ) competing in the 18 \& Under or 14 \& Under British National Championships (Nottingham, England) or Lawn Tennis Association Winter Series (Bisham Abbey, England). All subjects were nationally ranked junior tennis players ranging in age from 11 to $18 \mathrm{yr}$. $(M=13.9 \mathrm{yr}$.; $S D=1.8 \mathrm{yr}$.). Of those players invited to participare, $90.91 \%$ complied.

Measurement of Competition State Anxiety

Competition state anxiety was measured using the Competitive State Anxiety Inventory-2 (Martens, et al., 1990), a sport-specific questionnaire 
comprising 27 items pertaining to three subscales of Cognitive Anxiety, Somatic Anxiety, and Self-confidence. Subjects responded to items, for example, "I am concerned about this competition," by indicating one of four response categories from 1 ("not at all") to 4 ("very much so"). Hence, each subscale score was in the range of 9 to 36 .

\section{Interventions}

Subjects completed one of four intervention conditions. A cognitive intervention group $(n=24)$ completed a mental rehearsal technique lasting 15 minutes, in which subjects visualised themselves performing perfectly during their forthcoming match, using a first-person perspective of imagery (see Syer \& Connolly, 1984). ${ }^{2}$ A somatic intervention group $(n=25)$ completed 10 minutes of centering (see Nideffer, 1976). A cognitive and somatic intervention group $(n=25)$ completed centering followed by mental rehearsal. This intervention condition, lasting 25 minutes, was included to evaluate the notion that interventions aimed at both modalities of anxiety would be superior to those aimed at either one.

The control group $(n=26)$ completed a concentration grid exercise (Harris \& Harris, 1984). The task required subjects to check off numbers from a 10 by 10 grid, containing all numbers between 00 and 99 , in ascending order starting from a randomly specified number. The concentration grid was chosen as the control condition because it demands attentional control but is not advocated by Harris and Harris (1984) as an anxiety control intervention. It was hypothesised that the attentional demands of such a task would have some anxiety-reduction qualities, because attention would be distracted from negative self-evaluation but would be less effective than the other conditions.

A consistent theme in applied sport psychology is that interventions need to be introduced and practised over weeks or even months to maximize their effectiveness. The rationale for employing such brief intervention techniques was to explore the possibility that significant reductions in anxiety could be achieved with little investment of time and effort. If short interventions show potential to reduce anxiety without requiring lengthy periods of training, this has substantial implications for the choice of intervention strategy applied by sport psychologists.

\section{Procedure}

Subjects were stratified randomly by gender and age to one of the four experimental groups. They first completed the Competitive State Anxiety Inventory-2, using standardised instructions recommended by Martens, et

\footnotetext{
${ }^{2}$ Scripts for all interventions can be obtained by writing to the first author.
} 
al. (1990). Subjects were then instructed individually how to complete their intervention which was provided on audiocassette. In a quiet location, subjects performed their assigned intervention technique as they listened to the cassette using a personal stereo and headser. A researcher monitored the subjects' performance of the intervention. All subjects confirmed that the interventions had been understood and followed. Following the intervention, subjects again completed the Competitive State Anxiety Inventory-2.

\section{REsults ANd Discussion}

Descriptive statistics for pre- and postintervention test scores grouped by type of intervention are contained in Table 1. The effectiveness of the four interventions is presented graphically in Figs. 1, 2, and 3. Cognitive anxiety scores were reduced $13.09 \%$ over-all following intervention, with centering achieving an $18.21 \%$ reduction, mental rehearsal a $15.62 \%$ reduction, the combined intervention a $12.56 \%$ reduction, and the concentration

TABLE 1

Competitive State Anxiety Inyentory-2 Subscale Scores Preand Postintervention Grouped by Type of Intervention

\begin{tabular}{|c|c|c|c|c|c|}
\hline \multirow[t]{2}{*}{ Subscale/Condition } & \multirow[t]{2}{*}{$n$} & \multicolumn{2}{|c|}{ Preintervention } & \multicolumn{2}{|c|}{ Postintervention } \\
\hline & & $M$ & $S D$ & $M$ & $S D$ \\
\hline \multicolumn{6}{|l|}{ Cognitive Anxiety } \\
\hline Centering & 25 & 14.7 & 4.0 & 12.0 & 3.9 \\
\hline Rehearsal & 24 & 14.9 & 3.5 & 12.6 & 3.4 \\
\hline Centering/Rehearsal & 25 & 16.6 & 4.3 & 14.5 & 5.2 \\
\hline Control & 26 & 14.0 & 3.1 & 13.2 & 2.9 \\
\hline \multicolumn{6}{|l|}{ Somatic Anxiety } \\
\hline Centering & 25 & 19.5 & 4.9 & 17.4 & 5.1 \\
\hline Rehearsal & 24 & 19.3 & 4.5 & 16.6 & 4.8 \\
\hline Centering/Rehearsal & 25 & 20.3 & 5.4 & 18.5 & 6.1 \\
\hline Control & 26 & 17.9 & 3.8 & 17.4 & 5.3 \\
\hline \multicolumn{6}{|l|}{ Self-confidence } \\
\hline Centering & 25 & 27.2 & 4.4 & 30.0 & 3.8 \\
\hline Rehearsal & 24 & 26.3 & 5.0 & 28.5 & 6.1 \\
\hline Centering/Rehearsal & 25 & 25.8 & 5.1 & 29.0 & 5.4 \\
\hline Control & 26 & 26.8 & 5.2 & 27.2 & 5.6 \\
\hline
\end{tabular}

grid a $6.05 \%$ reduction (see Fig. 1). Maynard and Cotton (1993) reported a comparable reduction in scores on Cognitive Anxiety (13.89\%) following a course of applied relaxation, although a course of positive thought control produced a $32.89 \%$ decrease. It should be remembered, however, that the applied relaxation and positive thought-control courses lasted 12 weeks, whereas the interventions in this study took only 10 to 25 minutes each.

Somatic anxiety scores fell by $9.19 \%$ over-all, with centering producing a $10.47 \%$ reduction, mental rehearsal a $14.23 \%$ reduction, the combined in- 


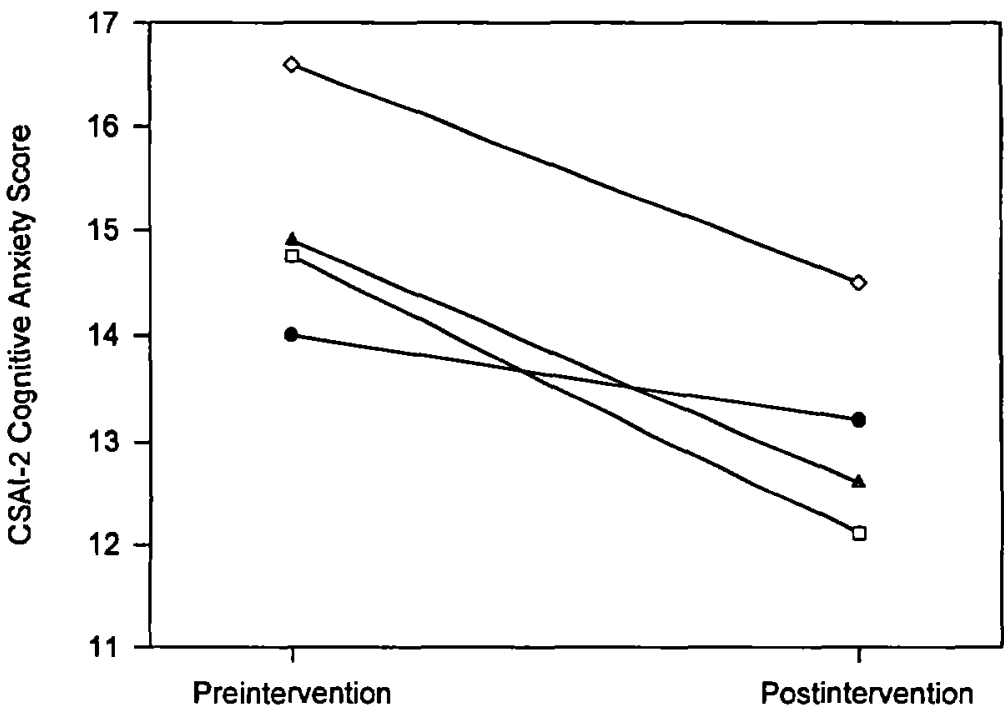

Time of Test

FIG. 1. Competitive State Anxiety Inventory-2 Cognitive Anxiety comparisons for four conditions of intervention: Centering ( $\square, n=25)$, Rehearsal ( $\wedge, n=24)$, Centering/Rehearsal $(0, n=25)$, and Control $(\bullet, n=26)$

tervention a $9.06 \%$ reduction, and the concentration grid a $3.01 \%$ reduction (see Fig. 2). Maynard and Cotton (1993) reported reductions in ratings on Somatic Anxiety of $16.73 \%$ and $32.7 \%$ following positive thought control and applied relaxation, respectively. Rated Self-confidence was enhanced in the present study by $8.07 \%$ over-all following intervention, with centering producing a $10.44 \%$ increase, mental rehearsal an $8.41 \%$ increase, the combined intervention a $12.38 \%$ increase, and the concentration grid a $1.42 \%$ increase (see Fig. 3). Although it can be seen that the interventions in this study were less efficacious anxiety-reduction techniques than the 12-wk. courses, the fact that a brief period of centering or mental rehearsal can reduce anxiety confirms them as efficient and valuable intervention strategies.

Scores on the Competitive State Anxiety Inventory-2 subscales were compared across time and among the four intervention conditions by means of a $4 \times 2$ (group $\times$ time) multivariate analysis of variance with repeated measures on the time factor. The results are contained in Table 2. Multivariate analysis of variance indicated no significant main effect by group but confirmed significant reductions in mean Somatic Anxiety scores $\left(F_{1.96}=39.23\right.$, $p<.001)$ and Cognitive Anxiety scores $\left(F_{1.96}=45.20, p<.001\right)$ and a signifi- 


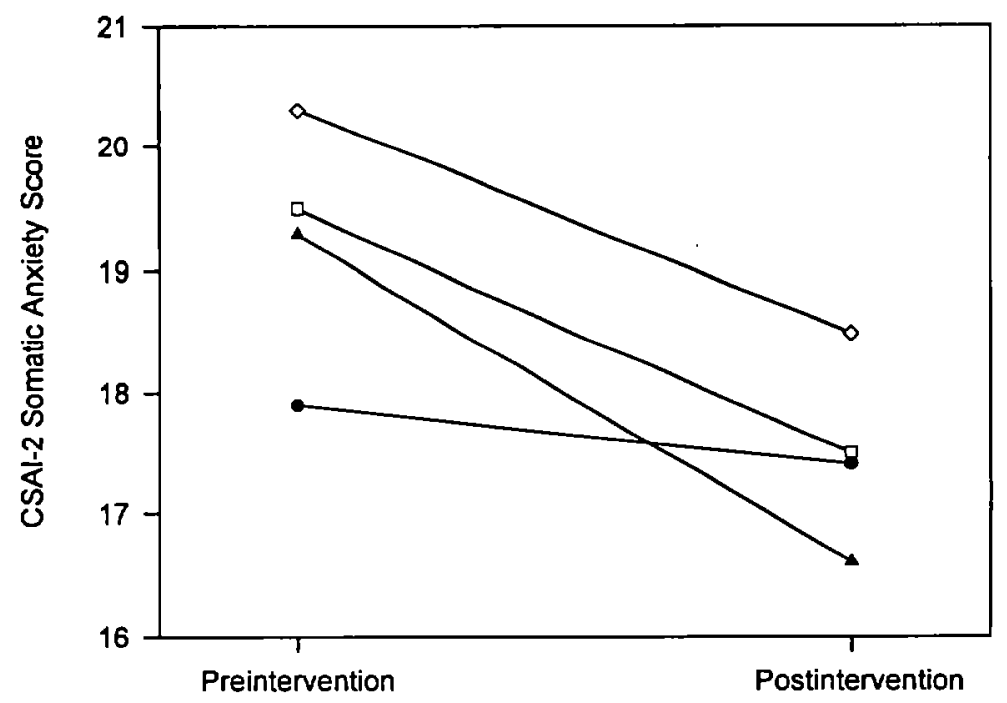

Time of Test

FIG. 2. Competicive State Anxiety Inventory-2 Somatic Anxiety comparisons for four conditions of intervention: Centering ( $\square, n=25)$, Rehearsal ( $\wedge, n=24)$, Centering/Rehearsal $(0, n=25)$, and Control $(\bullet, n=26)$

cant increase in rated Self-confidence $\left(F_{1.96}=49.02, p<.001\right)$ following intervention. No significant interaction effect was evident for rated Cognitive Anxiety with all groups showing reduced scores following intervention, whereas a significant interaction for group by time emerged for rated Selfconfidence $\left(F_{3,96}=4.23, p<.007\right)$. This interaction effect showed that ratings of Self-confidence were enhanced by centering, mental rehearsal, or a combination of the two but not by the control condition. The interaction effect for scores on Somatic Anxiety fell just short of the required alpha level $\left(F_{3,96}=2.63, p=.06\right)$. Again, all groups showed reduced ratings of Somatic Anxiety following intervention.

Although the preintervention anxiety measures show between-group variation, univariate one-way analysis of variance indicated that there were no significant between-group differences at the pretest stage or at the posttest stage for any of the anxiety subscales.

This study investigated the relevance of the matching hypothesis for anxiety interventions in tennis. The results show that significant reductions in preperformance anxiety scores can be achieved through a variety of intervention strategies, including a control technique involving attentional distraction. The efficacy of these interventions did not vary significantly, except 
in the case of rated self-confidence. These results do not support the findings of Maynard and Cotton (1993) and question the proposed need (Gould, et al., 1984; Jones, 1992) to match the nature of the intervention strategy to the anxiety symptoms experienced.

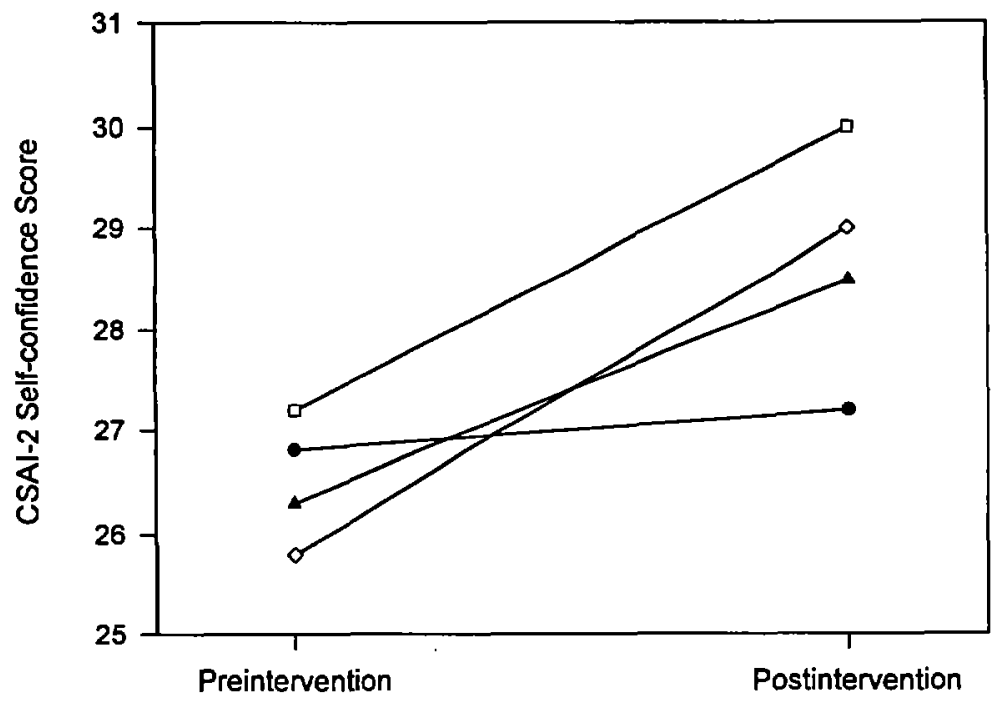

Time of Test

Fig. 3. Competitive State Anxiety Inventory-2 Self-confidence comparisons for four conditions of intervention: Centering $(\square, n=25)$, Rehearsal $(\wedge, n=24)$, Centering/Rehearsal $(0$, $n=25)$, and Control $(\bullet, n=26)$

Over-all, centering proved the most effective intervention in reducing ratings of Cognitive Anxiety, whereas mental rehearsal reduced Somatic Anxiety scores most, the very opposite of what might have been expected if the matching hypothesis held true. This strongly supports the notion of a crossover effect (Burton, 1990; Maynard \& Cotton, 1993), whereby interventions to reduce somatic symptoms also reduce cognitive symptoms and vice versa. In this instance, it appears that the physical control induced by centering significantly reduced worry, and the positive images generated by mental rehearsal had a significant calming effect upon somatic functioning. There was little apparent advantage in using both techniques in preference to either one. Rated Self-confidence was the only anxiety subcomponent for which the combined intervention proved superior to either component part.

The concentration grid, used as a control condition, was effective in reducing Cognitive Anxiety ratings and, to less extent, Somatic Anxiety rat- 
ings. This can be explained in terms of the proposed source of anxiety, which involves a perceived imbalance between task demand and response capability exacerbated by awareness of heightened somatic responses (Martens, et al., 1990). Attentional control exercises and indeed all anxiety-reduction techniques divert attention away from negative comparisons between task demands and perceived ability and thereby appear to reduce anxiety.

TABLE 2

Group ay Time Multivariate Analysis of Variance For Competitive State Anxiety Inventory-2 Subscale Scores

\begin{tabular}{lccc}
\hline \hline Measure & $d f$ & $M S$ & $F$ \\
\hline Cognitive Anxiety & & & \\
$\quad$ Group & 3,96 & 48.20 & 1.91 \\
Time & 1,96 & 196.83 & $45.2 \dagger^{\dagger}$ \\
Interaction & 3,96 & 8.15 & 1.87 \\
Somatic Anxiety & & & \\
$\quad$ Group & 3,96 & 29.42 & 0.64 \\
Time & 1,96 & 160.46 & $39.23 \dagger$ \\
Interaction & 3,96 & 10.74 & 2.63 \\
Self-confidence & & & \\
Group & 3,96 & 25.50 & 0.54 \\
Time & 1,96 & 232.71 & $49.02 \dagger$ \\
Interaction & 3,96 & 20.09 & $4.23^{*}$ \\
\hline
\end{tabular}

${ }^{*} p<.01 . \dagger p<.001$.

The usefulness of centering and mental rehearsal may be especially pertinent to sports such as tennis, where relatively short bursts of intense action are interspersed with frequent recovery periods. These recovery periods allow ample time for implementing the techniques during performance should they be perceived as necessary. It should be acknowledged that the uncertainty surrounding anxiety-performance relationships dictates that anxiety reduction will not necessarily benefit performance. For the under-aroused athlete, clearly it may prove detrimental. Hence, the interventions in this study are not advocated as performance enhancing strategies per se. What is proposed is that a well-learned anxiety-reduction technique is a useful competition skill for any performer to possess and that determining exactly how and when the technique should be implemented is a key function for the practitioner in sport psychology.

Psychological momentum has been shown to fluctuate substantially in junior tennis (Edwards, Terry, \& Weinberg, 1992). Hence, changes in state anxiety once the match has commenced are likely and may be more influential upon outcome than prematch anxiety. This emphasizes the need, also noted by Hardy and Jones (1994), to develop effective strategies for assessing state anxiety during performance to enhance further understanding of 
anxiety-performance relationships. It also emphasizes that interventions which cannot be utilised during a tennis match may have limited usefulness for performers.

It can be concluded that both cognitive and somatic interventions have the capacity to reduce significantly cognitive and somatic anxiety and to increase self-confidence. The proposed need to match intervention to anxiety subcomponent was not supported. It should be noted that the ages of subjects in the present study suggest that the results may not generalize to older populations.

The effectiveness of the control condition in reducing cognitive and somatic anxiety scores leads to the conclusion that an intervention which directs attentional focus away from self-evaluation may have a beneficial effect upon state anxiety. This is consistent with the first author's practitioner experience at three Olympic Games and several World Championships that many elite athletes use attentional distraction as part of effective precompetition routines.

It is also concluded that techniques for control of anxiety which require relatively little time and effort to master should be taught early during mental training programmes. More lengthy and elaborate techniques should be reserved for situations wherein techniques such as centering and mental rehearsal have proved ineffective.

\section{REFERENCES}

Borkovec, T. D. (1976) Physılogical and cognitive processes in the regulation of anxiety. In G. Schwarz \& D. Shapiro (Lds), Consciousness and self-regulation: advances in research. New York: Plenum. Pp. 31-51.

Burton, D. (1990) Multimodal stress management in sport: current status and future direccions. In J. G. Jones \& L. Hardy (Eds.), Stress and performance in sport. New York: Wiley. Pp. 171-202.

Dandion, R. J., \& Schwartz, G. E. (1976) The psychobiology of the relaxation and related states: a multiprocess theory. In D. I. Mostofsky (Ed.), Bebavior control and modification of physiological activity. Englewood Cliffs, NJ: Prentice-Hall. Pp. 399-442.

Edwards, T., Terry, P. C., \& Weingerg, R. S. (1992, July) Antecedents and predictors of psychological momentum in tennis. Paper presented at the North American Society of Psychology in Sport and Physical Activity, Pittsburgh, PA.

Gould, D., Petlichkoff, L., \& Weingerg, R. S. (1984) Antecedents of temporal changes in, and relationship between CSAI-2 subcomponents. Journal of Sport Psycbology, 6, 289. 304.

Hardy, L., \& Jones, J. G. (1994) Current issues and furure directions for performance related research in sport psychology. Journal of Sports Sciences, 12, 61-92.

Harris, D. V., \& Harrus, B. L. (1984) The atblete's guide to spont psychology: mental skills for physical people. New York: Leisure Press.

Jones, J. G. (1992) Stress and anxiety. In S. J. Bull (Ed.), Sport psychology: a self-belp guide. London: Crowood Press. Pp. 31-51.

Martens, R., Burton, D., Vealey, R. S., Bump, L. A., \& Smith, D. E. (1990) The Competitive State Anxiety Inventory-2 (CSAI-2). In R. Martens, R. S. Vealey, \& D. Burton (Eds.), Competitive anxiety in sport. Champaign, IL: Human Kinetics. $P_{\mathrm{P}}$. 117-190.

Maynard, 1. W., \& Cotton, P. C. (1993) An investigation of two stress-management techniques in a field setting. The Sport Psychologist, 7, 375-387. 
Nideffer, R. (1976) The inner athlete. New York: Crowell.

Ost, L. G., Jerremalm, A., \& Johansson, J. (1988) Individual response patterns and the effects of different behavioural methods in the treatment of social phobia. Scandinavian Journal of Behavioural Research and Therapy, 19, 1.16.

SuInN, R. M. (1987) Behavioral approaches to stress management in sport. In J. R. May \& M. J. Asken (Eds.), Spart psychology. New York: PMA. Pp. 59-75.

Syer, ]., \& Connolly, C. (1984) Sporting body, sporting mind. London: Cambridge Univer. Press.

Accepted July 7, 1995. 